Informes de la Construcción Vol. 62, 517, 37-51, enero-marzo 2010 ISSN: 0020-0883 elSSN: 1988-3234 doi: 10.3989/ic.09.067

\title{
La sostenibilidad en la arquitectura industrializada: cerrando el ciclo de los materiales
}

\author{
Sustainability in industrialised architecture: closing the \\ materials cycle
}

G. Wadel $^{(*)}$, J. Avellaneda ${ }^{(* *)}$, A. Cuchí ${ }^{(* *)}$

\section{RESUMEN}

La condición de sostenibilidad, desde el punto de vista físico, puede ser definida como el cierre de los ciclos materiales, alcanzándose éste en un sistema determinado cuando no existen flujos de residuos sino que los recursos se reciclan constantemente. Tal condición encuentra un fuerte obstáculo en el modelo productivo que caracteriza a la mayor parte de la industria contemporánea, nacido en la revolución industrial, que puede sintetizarse en la secuencia lineal extracción $>$ fabrica ción $>$ uso $>$ residuo. En oposición a ello, el modelo productivo en el que se centra la investigación que aquí se presenta ${ }^{1}$ es la ecología industrial y se basa en el ejemplo de la biosfera como máquina de reciclar. Supone la eliminación del concepto de residuo y puede resumirse en el ciclo continuo de reciclaje-fabricación-uso-reciclaje.

La hipótesis planteada consiste en que, a partir de los sistemas de construcción modular ligera que se comercializan bajo el sistema de alquiler (que hace posible que los módulos regresen a la fábrica una vez cumplida su vida útil, recuperándose sus componentes) se puede desarrollar un sistema de gestión de los recursos empleados en el ciclo de vida de los edificios capaz de cerrar los ciclos materiales hasta en un 90\% (en la construcción convencional se alcanza un $10 \%$ ).

\section{$113-87$}

Palabras clave: sostenibilidad, impacto ambiental arquitectura industrializada, construcción modular, ciclo de los materiales.

\section{SUMMARY}

The condition of sustainability, from a physical point of view, can be defined as the closure of the material cycle. This is reached in determined systems, in the absence of residual flows, and in which resources are constantly recycled. Such systems can encounter serious obstacles in the productive model that characterises the majority of contemporary industry. The productive model, born during the Industrial Revolution, can be summarised by the following lineal sequence: extract ion $>$ manufacture $>$ use $>$ residue. In contrast, this research ${ }^{1}$ focuses on a productive model from the ecological industry, based on the example of the biosphere as a recycling machine. Requiring the elimination of the concept of residues, the system can be summarised by the following continuous cycle: recycling-manufacturing-use-recycling.

The hypothesis posed is as follows: using technology presently available, represented by the lightweight modular construction that is commercialised by renting (making it possible to return the modules to the factory once their useful life is over, therefore recuperating resources), a management system capable to close the material cycle at least to $90 \%$ can be developed. (conventional building construction currently manages a recycling value of $10 \%$ of used resources).

Keywords: sustainability, environmental impact, industrialised architecture, modular construction, materials cycle.
${ }^{1}$ Los temas tratados en este artículo se encuentran desarrollados extensamente en la tesis doctoral "La sostenibilidad en la arquitectura industrializada. La construcción modular ligera aplicada a la vivienda", cuyo autor, director y tutor respectivamente son: G. Wadel, J. Avellaneda y A. Cuchí. (Universidad Politécnica de Cataluña, Departamento de Construcciones Arquitectónicas 1, Programa de Doctorado Ámbitos de Investigación en la Energía y el Medio Ambiente en la Arquitectura).

\footnotetext{
(*Sociedad Orgànica, Cataluña (España)

${ }^{(* *}$ Universidad Politécnica de Cataluña (España)
} 


\section{SOSTENIBILIDAD AMBIENTAL Y ARQUITECTURA}

Si bien existen numerosos antecedentes de la detección y manifestación de los problemas ambientales causados por la sociedad industrial, es hacia 1987 y con la aparición del informe Nuestro futuro común ${ }^{2}$, cuando se produce un primer acuerdo mundial sobre la concepción contemporánea del problema ambiental, con la incorporación del concepto de sostenibilidad -más concretamente el desarrollo sostenible- al ideario de muchas disciplinas, entre ellas también la arquitectura.

${ }^{2}$ Comisión mundial sobre el Medio Ambiente y el Desarrollo de la Organización de las Naciones Unidas, Our Common Future, 1987. También conocido como informe Bruntland.

${ }^{3}$ Enfoque que compara los sistemas industriales con los ecosistemas naturales, entendiendo los flujos de materiales como un metabolismo en que los residuos de una actividad pueden ser los recursos de sí misma, o bien de otra.

${ }^{4}$ El capital natural puede ser definido como el conjunto formado por los recursos naturales con que cuenta el planeta, en su orden y calidad originales $y$, por tanto, con una utilidad social específica.

${ }^{5}$ Véanse, por ejemplo, las estimaciones de la red de científicos y técnicos Global Footprint Network que calcula de forma actualizada la huella ecológica de diversos países y global. www. footprintnetwork.org

${ }^{6}$ La entropía mide la parte de la energía que no puede utilizarse para producir trabajo. Es central para la segunda Ley de la Termodinámica, que sostiene que existe una tendencia natural hacia la máxima dispersión y mezcla de los recursos, hasta llegar al estado termodinámicamente muerto.

${ }^{7}$ Considerando datos de IDAE para los sectores domésticos $y$ de servicios, más un 30\% estimado para la fase de extracción y fabricación de materiales.

${ }^{8}$ A. Cuchí y A. Pagés, Sobre una estrategia para dirigir al sector de la edificación hacia la eficiencia en la emisión de gases de efecto invernadero (GEI), Ministerio de Vivienda, octubre de 2007.
El concepto de sostenibilidad, que da origen a lo que podría llamarse como arquitectura sostenible, se basa en la definición de desarrollo sostenible de nuestro futuro común, resultando como la capacidad de satisfacer las necesidades de las generaciones presentes sin hipotecar la capacidad de las generaciones futuras para satisfacer sus propias necesidades. A partir de ello el crecimiento económico y su deterioro ecológico asociado quedaron indisolublemente ligados, cuestión que puede ejemplificarse fácilmente en el uso de los combustibles fósiles. No es sostenible nuestro desarrollo basado en el consumo y la contaminación causada por la combustión del petróleo, puesto que el agotamiento del recurso natural y la contaminación que supone condicionan severamente las posibilidades de las generaciones futuras, a quienes obligamos a hacerse cargo de las consecuencias de nuestras acciones.

La arquitectura se materializa a través de la construcción que, al igual que otras industrias, se basa en el modelo productivo dominante cuyo origen se remonta a la revolución industrial, hace unos doscientos cincuenta años. Hasta entonces la sociedad era fundamentalmente orgánica y se caracterizaba por un uso predominante de recursos biosféricos, ajustándose, con algunas excepciones, a la capacidad de la naturaleza para producirlos así como a sus posibilidades para asimilar los residuos generados.

Con la disposición indiscriminada de fuentes de energía (primero el carbón, luego el petróleo, más tarde la energía nuclear) que permitieron acceder masivamente a los recursos minerales como nunca antes se había hecho, se puso en marcha una espiral de crecimiento ilimitado en el consumo de recursos y en la consiguiente generación de residuos (1). Esta aceleración, junto con el aumento de la renta per cápita, la explosión demográfica y la extensión del transporte horizontal han dado origen a otra forma de organización cultural, la sociedad industrial, donde cada material extraído de la litosfera acaba degradado y vertido sobre la delgada capa de biosfera que recubre el planeta, contaminándola y condicionando las condiciones para la continuidad de la vida.

El modelo productivo dominante, que como ha sido dicho caracteriza también a la producción de la arquitectura, puede sintetizarse en la secuencia lineal extracción $>$ fabricación>uso >residuo. Con la excepción de unas pocas industrias que basan su organización en la llamada ecología industrial ${ }^{3}$, un metabolismo de producción que imita las condiciones de la biosfera donde la palabra residuo no existe, todo producto es diseñado para convertirse finalmente en un residuo. Una moqueta puede durar diez años, una ventana treinta y un edificio setenta, pero todos acabarán convertidos en residuos porque responden a un mismo paradigma productivo lineal, ignorando que esa conversión de recursos a desperdicios implica una disminución, lenta pero inexorable, de lo único verdaderamente valioso de que disponemos: el stock de capital natural ${ }^{4}$ con que cuenta el planeta.

Por oposición y recurriendo nuevamente al ejemplo de la biosfera, la gran máquina de reciclar, la arquitectura podría -y este artículo pretende aportar fundamentos para avanzar en esa línea- basarse en un modelo productivo alternativo aunque tan antiguo como la propia tierra. Se trata del cierre de los ciclos materiales (Figura 1), donde todos los ciclos abiertos de los sistemas de producción que generan residuos al aire, al agua o a la tierra comienzan a cerrarse bajo la consigna de eliminar la palabra residuo y sustituirla por recurso (2). El modelo productivo resultante no es ya lineal sino cíclico y queda definido por el ciclo reciclaje-fabricación-uso-reciclaje.

\section{IMPACTO AMBIENTAL DEL SECTOR DE LA EDIFICACIÓN}

Las principales causas del impacto ambiental de la arquitectura se encuentran en el consumo de recursos no renovables y en la generación de residuos contaminantes, ambos en aumento acelerado ${ }^{5}$. Su principal efecto es el aceleramiento de la destrucción del stock de capital natural (3) por degradación entrópica ${ }^{6}$, algo que resulta especialmente tangible cuando observamos sus efectos más visibles o conocidos, como la tala de los bosques nativos, el agotamiento de los combustibles fósiles, la disminución de las reservas de agua dulce, o la contaminación de la atmósfera por la emisión de gases que se traducen en el efecto invernadero, la lluvia ácida y la destrucción de la capa de ozono. 
La construcción y el uso de los edificios en España, en el contexto del total de impactos de la sociedad, supone:

-Un 32\% del consumo de energía ${ }^{7}$, principalmente no renovable.

- Un 30\% de la generación de emisiones de $\mathrm{CO}_{2}{ }^{8}$, de efecto invernadero.

- Un 24\% de las extracciones de materiales ${ }^{9}$ de la corteza terrestre.

-Entre el $30 \%$ y el $40 \%$ de los residuos sólidos generados ${ }^{10}$.

-El 17\% del agua potable consumida ${ }^{11}$.

Además, existen otros impactos ambientales en los que intervienen los procesos industriales de extracción y fabricación de materiales, la combustión de energía para su transporte, los procesos de generación energética para los consumos del uso de

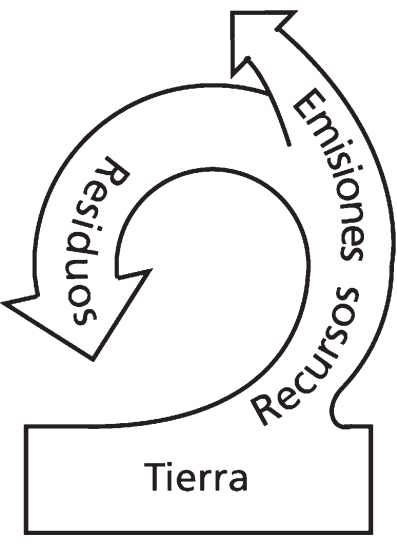

SXX: Ciclos materiales abiertos

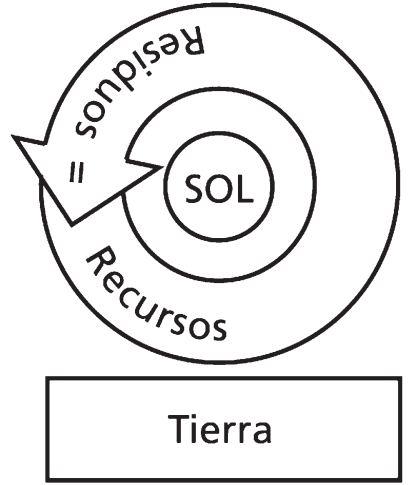

SXXI: Ciclos materiales cerrados

\begin{tabular}{|c|c|c|c|}
\hline Valores actuales & Mejora & Valores óptimos & Referencias \\
\hline $\begin{array}{l}\text { Energía } \\
3.059 \mathrm{kgCO}_{2} / \text { vivienda/año }\end{array}$ & $40 \%$ & $1.875 \mathrm{kgCO}_{2} /$ vivienda/año & $\begin{array}{l}\text { Niveles de cumplimiento del Protocolo de Kioto } \\
\text { y del Plan de Energía de Cataluña. }\end{array}$ \\
\hline $\begin{array}{l}\text { Agua } \\
168 \text { litros/persona/día }\end{array}$ & $50 \%$ & persona/día & $\begin{array}{l}\text { Estudios diversos (Generalitat de Cataluña y } \\
\text { Fundación Ecología y Desarrollo). }\end{array}$ \\
\hline $\begin{array}{l}\text { Materiales } \\
2.792,8 \mathrm{~kg} / \mathrm{m}^{2}, 9.070 \mathrm{MJ} / \mathrm{m}^{2} \\
\text { y } 750 \mathrm{kgCO} 2 / \mathrm{m}^{2}\end{array}$ & $? \%$ & $\begin{array}{l}\text { Existen proyectos de vivienda } \\
\text { pública en Cataluña que se } \\
\text { sitúan en } 1.700 \mathrm{~kg} / \mathrm{m}^{2}, 4.500 \\
\mathrm{MJ} / \mathrm{m}^{2} \text { y } 400 \mathrm{kgCO} / \mathrm{m}^{2}\end{array}$ & $\begin{array}{l}\text { Según un estudio del CIES (grupo formado por } \\
\text { los colegios de arquitectos i aparejadores, la } \\
\text { UPC, el ITeC y el Institut Cerdà) y otros } \\
\text { estudios de evaluación ambiental de proyectos } \\
\text { específicos. }\end{array}$ \\
\hline $\begin{array}{l}\text { Residuos } \\
120 \mathrm{~kg} / \mathrm{m}^{2} \text { obra nueva } \\
320 \mathrm{~kg} / \mathrm{m}^{2} \text { rehabilitación }\end{array}$ & $\sqrt{55 \%}$ & $\begin{array}{l}10 \% \text { de reducción y } 50 \% \text { de } \\
\text { reciclaje }\end{array}$ & $\begin{array}{l}\text { Objetivos del PROGROC (Programa de gestió } \\
\text { de residus de la construcció de Catalunya) y } \\
\text { experiencias de buenas prácticas. }\end{array}$ \\
\hline
\end{tabular}

los edificios y, finalmente, la generación de residuos de derribo, cuya cuantificación a escala global resulta menos sencilla que los anteriores. Entre otros pueden citarse:

- La ecotoxicidad y la toxicidad humana causada por las emisiones de sulfuro, óxidos del nitrógeno, amoníaco y metales pesados que, precipitándose por medio de las Iluvias ácidas, aumentan la acidificación y la toxicidad del suelo y las aguas.

- Aunque bajo control actualmente, la reducción de la capa de ozono producida por la liberación de gases CFC (clorofluorocarbonos) y HCFC (hidroclorofluorocarburos) que formaban parte de líquidos refrigerantes, agentes extintores e impulsores para aerosoles.

- La eutrofización, desequilibrio de nutrientes en un ecosistema acuático, causado por emisiones y vertidos de compuestos ricos en nitrógeno y fósforo en la tierra y el agua.

-El smog, formado por emisiones de dióxido de carbono, partículas sólidas y dióxido de sulfuro liberadas por la combustión del carbón (centrales eléctricas, calderas, etc.). Aunque existen sistemas más complejos y completos, en el sector de la edificación hay un cierto consenso ${ }^{12}$ acerca de los parámetros que pueden tenerse en cuenta a la hora de evaluar en forma resumida su impacto ambiental de los edificios a través del estudio de sus flujos materiales: energía, agua, materiales y residuos. Los diseñadores de edificios, los arquitectos, habitualmente están más preparados para entender las leyes de generación y comportamiento de los stocks de recursos con los que se trabaja en su materialización, que con los flujos que ellos suponen. Tanto el análisis de estos últimos como el entendimiento de las nuevas unidades de medida de la dimensión ambiental de la arquitectura suponen un esfuerzo de comprensión que es una muestra del ensanche que la profesión está experimentando al incorporar la consideración de la sostenibilidad ambiental en la arquitectura.

Haciendo uso de la información disponible en España ${ }^{13}$, seguidamente se intentará cuantificar el impacto ambiental de la edificación de viviendas, determinando los flujos de energía, agua, materiales y residuos (Figura 2).

- La energía: la fabricación de los materiales
necesarios para construir un metro cuadra-
1. El ciclo de los materiales.

2. Impactos ambientales de la edificación convencional. El margen de mejoras se sitúa entre el $40 \%$ y el $55 \%$, según el indicador.

${ }^{9}$ Wuppertal Institute.

${ }^{10}$ Informes del PROGROC, Programa de Gestió de Residus d'Obres de Construcció de Cataluña.

${ }^{11}$ Estadísticas e informes del Ministerio de Medio Ambiente, Medio Marino y Rural.

${ }^{12}$ Véase, por ejemplo, el proyecto Factor 10 del estudio SaAS (www.saas.cat)

${ }^{13}$ F. Mañà, A. Cuchí, D. Castelló, G. Diez, A. Sagrera, Parámetros de sostenibilidad, ITeC, 2003, catálogo de la exposición Habitar el Mundo del Forum Barcelona 2004, Estadística del Ministerio de Medio Ambiente, Medio Rural y Marino y también datos de elaboración propia. 
${ }^{14}$ LIDER, Ecotect, Energy Plus, Trnsys, CALENER, entre otros. ${ }^{15}$ Programa del ITeC, fichas técnicas del Colegio de Arquitectos de Cataluña, etc.

${ }^{16}$ Banco BEDEC PR/PCT del ITeC, Agenda de la Construcción sostenible, Producto sostenible, etc.

${ }^{17}$ Institut Cerdà, Guía de la Edificación sostenible, Gobierno Vasco, Guía de la edificación sostenible para la vivienda, etc.

${ }^{18}$ VERDE, del Green Building Council España; LEED del U.S. Green Building Council; GBTools del Green Building Challenge, BREEAM y EcoHomes del Building Research Institute; etc.

${ }^{19}$ Por ejemplo, la obtención de la más alta puntuación del sistema de certificación ambiental de edificios LEED (categoría platinum) no necesariamente supone que en él se cierren los ciclos materiales.

${ }^{20} \mathrm{De}$ acuerdo con las previsiones del IPCC (Panel Intergubernamental Contra el Cambio Climático) y de la ONU (Organización de las Naciones Unidas), si se tienen en cuenta factores tales como a) el nivel de emisiones de $\mathrm{CO}_{2}$ de la sociedad en la actualidad, b) la máxima concentración posible de emisiones de $\mathrm{CO}_{2}$ que puede alcanzarse en la atmósfera sin que se produzca un aumento de la temperatura global que ponga en riesgo la continuidad de la biodiversidad actual y c) el crecimiento de población estimado, para neutralizar el impacto ambiental de las emisiones de $\mathrm{CO}_{2}$ hacia 2020 es necesario alcanzar un $90 \%$ de reducción sobre los niveles actuales. A partir de ello, un edificio que cumple el Código Técnico de la Edificación y, de acuerdo con las previsiones de sus autores, alcanza una reducción de consumo energético del orden del 35\% respecto de las edificaciones previas a su entrada en vigencia, pudiendo esperarse una reducción similar en emisiones de $\mathrm{CO}_{2}$, se encuentra muy lejos de la condición de neutralización del impacto (y mucho más aún si se tiene en cuenta que por cada edificio nuevo hay miles existentes, a los cuales el CTE no afecta). En síntesis y haciendo una gran simplificación, un edi- do de edificación estándar puede suponer el consumo de energía equivalente a unos $6.000 \mathrm{MJ}$ (unos $1.670 \mathrm{kWh}$ ) que equivalen a 150 litros de gasolina. El uso del mismo edificio, en condiciones habituales, durante el período de un año y también expresado por metro cuadrado puede llegar a los 500 MJ (unos $140 \mathrm{kWh}$ ), que representan unos 12 litros de gasolina. Considerando la energía del uso del edificio para una vida útil de 50 años y sumándola a la de producción de los materiales, se llega a un valor total de $30.000 \mathrm{MJ} / \mathrm{m}^{2}$ (unos $8.330 \mathrm{kWh} / \mathrm{m}^{2)}$ o bien 755 litros de gasolina $/ \mathrm{m}^{2}$.

- El agua: en una vivienda convencional cada día ingresa un volumen promedio de 160 litros de agua potable por persona, de la que más del $90 \%$ se utiliza como un vehículo para transportar ciertos residuos lejos del hogar. En efecto, apenas un 10\% del agua purificada que consumimos se bebe o se utiliza para cocinar, aunque toda ella acaba convertida en agua residual y por tanto no es apta para ningún otro uso, debiendo ser depurada antes de devolverse al ciclo hidrológico, desde donde será vuelta a captar.

- Los materiales: La construcción de un metro cuadrado habitable de edificación estándar, haciendo de momento abstracción del mantenimiento y la rehabilitación durante la vida útil de los edificios, supone la utilización de $2.500 \mathrm{~kg}$ de materiales que ingresan directamente a la obra, con una gran cantidad de impactos ambientales asociados. Si además consideráramos la mochila ecológica -la cantidad de residuos que han sido generados durante la extracción de las materias primas y la fabricación de los productos- el valor original debería multiplicarse al menos por tres, con lo que llegaría una cifra de 7.500 kg/m².

- Los residuos sólidos. actualmente la construcción, el mantenimiento y el derribo de edificios implican una cantidad de residuos equivalente a $3 \mathrm{~kg}$ por persona y por día, de los que apenas se recicla un $10 \%$. Los residuos domésticos, por su parte, representan 1,7 kg también por persona y día, con una tasa de reciclaje que oscila alrededor del $15 \%$. El consumo energético de los edificios, señalado anteriormente, representa la generación de aproximadamente $2 \mathrm{~kg}$ de gas $\mathrm{CO}_{2}$, nuevamente por persona y día.

\section{ESTRATEGIAS PALIATIVAS O ESTRATEGIAS DEFINITIVAS}

Frente al panorama anteriormente descrito, en los últimos años han ido creándose herramientas de gran utilidad para conocer $y$ reducir el impacto ambiental de la edificación, tales como programas de simulación del comportamiento energético de los edificios $^{14}$, hojas de cálculo para residuos de construcción y demolición ${ }^{15}$, bases de datos de información ambiental sobre materiales ${ }^{16}$, manuales de construcción sostenible ${ }^{17} y$ sistemas de evaluación y certificación ambiental de edificios ${ }^{18}$, entre otras. Con ellas es posible determinar las causas y las consecuencias de ciertos efectos del impacto ambiental (principalmente el consumo de energía, la emisión de gases de efecto invernadero y la generación de residuos sólidos) que tendrán los edificios que se encuentran bajo análisis, especialmente en las fases de extracción y fabricación de los materiales y uso del edificio. Y, a partir de ello, también pueden determinarse qué soluciones alternativas de diseño de los espacios, de los sistemas constructivos o de los sistemas de instalaciones podrían tenerse en cuenta para modificar el proyecto y disminuir su impacto ambiental futuro.

Si bien todas estas herramientas son una muestra del extraordinario avance técnico disponible actualmente para actuar sobre el problema del impacto ambiental de la edificación, no debe olvidarse que su uso habitual, aunque permite disminuir los efectos ambientales negativos de los edificios, no asegura la neutralización de los impactos. Dicho de otra manera, el cumplimiento de los límites o valores que algunas de estas herramientas establecen permiten obtener mejoras parciales que, si bien pueden reducir la huella ecológica de los edificios, no eliminan el problema de fondo: un consumo de recursos y una generación de residuos que nuestro planeta no es capaz de soportar a largo plazo. El impacto ambiental, aunque en menor medida, continúa existiendo ${ }^{19}$.

Este desequilibrio ambiental, en cuya disminución las herramientas anteriormente enunciadas sin duda son de gran ayuda, no desaparecerá por completo porque es consecuencia directa del modelo productivo lineal aún vigente, cuya continuidad no es puesta en duda en los procesos de evaluación y mejora. De tal forma el enfoque con el que habitualmente se trabaja en el sector puede definirse como el de las estrategias de tipo paliativas o de disminución del problema, pudiéndose determinar a partir de ello otro enfoque que puede definirse como el de las estrategias definitivas o de neutralización del problema (Figura 3).

Teniendo en cuenta sólo un impacto ambiental para hacer más sencilla la comparación, la emisión de gases de efecto invernadero, el primer caso estaría representado por un edificio que las reduce, sin importar demasiado cuánto, mientras que el segundo lo estaría por un edificio que las reduce hasta 
alcanzar el nivel necesario para que, de acuerdo a su repercusión proporcional en el total global, se sitúe por debajo del límite a partir del que la acumulación de estos gases en la atmósfera afecta al clima ${ }^{20}$.

Si no cambia el modelo productivo lineal vigente no desaparece el problema ambiental ya que éste forma parte de él, está implícito en él. Tal modelo o paradigma de producción, la secuencia extracción $>$ fabricación $>$ uso $>$ residuo, ha ido sofisticándose con el tiempo, aunque sin modificar su esencia. Dicho de otro modo, es posible fabricar productos cada vez más complejos en menos tiempo, pero a costa de continuar aumentando la carga o la presión ambiental sobre el planeta. En esencia, a pesar de todos los cambios tecnológicos sucedidos desde el comienzo del aprovechamiento de la energía del vapor como trabajo mecánico, actualmente se produce del mismo modo que en la primera y la segunda revolución industriales. En estos tiempos, denominados usualmente como de la era digital, de la información, de las comunicaciones o simplemente llamados como la tercera revolución industrial, por mucho que se haya sofisticado el sistema productivo no se han abandonado sus rasgos esenciales: consumimos recursos a un ritmo varias veces superior al de su regeneración por parte del planeta y producimos residuos a un ritmo varias veces superior al de su absorción por parte del planeta. Y ambos son ritmos, además, crecientes. En consecuencia el desequilibrio del sistema natural que integramos, si no se redefine el sistema productivo desde una óptica ambiental, podrá retrasarse pero no evitarse.

La asunción del enfoque de las estrategias definitivas hace necesario que en el estudio del impacto ambiental de los edificios y en la determinación de sus oportunidades de mejora sea considerado el análisis del cierre de sus ciclos materiales, entendiendo por ello también la energía ${ }^{21}$. Y ello lleva a considerar una nueva dimensión de estudio, que es la gestión de los recursos aún más allá del ciclo de vida del edificio, desde su origen en la industria extractiva hasta su proceso final en la industria del vertido o del reciclaje, bajo el objetivo de establecer cuánto se acerca o se aleja del ciclo reciclaje-fabricación-usonuevo reciclaje.

\section{CLAVES PARA EL CIERRE DEL CICLO DE LOS MATERIALES EN LA EDIFICACIÓN}

Para cerrar el ciclo de los materiales en la edificación existen condicionantes de diversas clases: técnicos, de mercado, de gestión, de organización, culturales, económicos y

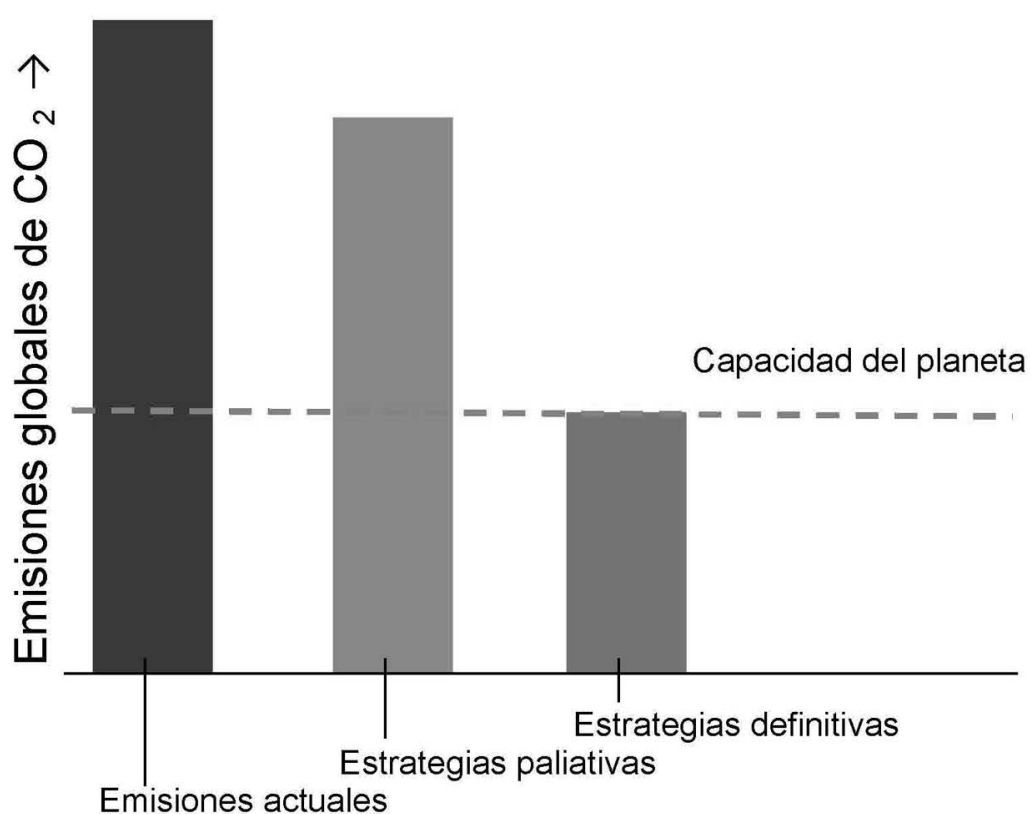

relativos a la propiedad y a la responsabilidad sobre los bienes (4).

La gran dispersión geográfica de la industria de la construcción, la gran cantidad de agentes que en ella intervienen tanto directa como indirectamente y un número muy grande de materiales, componentes y sistemas constructivos que coexisten en el mercado y forman parte de las obras dificultan las acciones que permitirían cerrar los ciclos materiales mediante el reciclaje, haciendo que la gran mayoría de ellos -con la excepción de unos pocos que puedan reutilizarse o reciclarsese conviertan en residuos.

A la complejidad de la organización del sector de la construcción y a la dificultad para llevar adelante acciones que sean capaces de controlar el consumo de materias primas y la generación de residuos se le suma otro problema, que es la dispersión de la propiedad de los recursos y, por tanto, de la responsabilidad sobre su gestión. Desde la extracción de los minerales hasta el vertido de los derribos, un gran número de personas físicas y jurídicas tienen el dominio de los recursos, que es traspasado sucesivamente bajo formas de organización física que van desde los materiales base hasta los edificios completos. En este proceso, en ningún momento la transacción incluye la responsabilidad de la gestión de los recursos empleados una vez que han perdido utilidad y por tanto valor monetario, momento en el que se convierten en residuos.

Asegurar la cadena de custodia en la responsabilidad de los materiales involucrados en la edificación es una de las claves en el proceso de gestión de los recursos para cerrar ciclos materiales. La cuestión central a resolver
3. Estrategias paliativas o estrategias definitivas, el caso de las emisiones de $\mathrm{CO}_{2}$.

ficio de cumplimiento normativo que alcanzara una reducción de emisiones de $\mathrm{CO}_{2}$ del orden del $35 \%$ se sitúa en las estrategias paliativas, mientras que sólo un edificio que las redujera en un $90 \%$, o directamente estuviera libre de ellas, se situaría en las estrategias definitivas.

${ }^{21}$ La energía no renovable que empleamos en los procesos industriales y de edificación está constituida por materiales (petróleo, gas natural, carbón, biomasa, etc.), así como la energía renovable necesita, en sus procesos de captación, transformación, acumulación y puesta en uso, de un soporte material. 
sería cómo lograr coordinar tantos agentes y tantos productos involucrados en las técnicas y procesos que intervienen en la construcción de los edificios, y ello además durante todas las etapas de su vida útil.

Quizás la clave esté en repensar cómo dar respuesta a la demanda de habitabilidad, entendiendo por ella el servicio que la edificación presta y la finalidad para la cual se construyen edificios. Quizás pueda entenderse más como un servicio, que como algo que se debe poseer. Más en el sentido dinámico, capaz de acompañar la variabilidad de la demanda en cuanto a su localización, sus características espaciales, los tiempos de residencia, la conformación de los grupos sociales que la demandan, etc., que como algo estático que lleva asociada la idea de la edificación inamovible, rígida en cuanto a la conformación de los espacios, gestionada en régimen de propiedad y, en consecuencia, con las dificultades comentadas anteriormente respecto del cierre de los ciclos materiales.

Es posible que el enfoque tradicional de lo que se entiende como habitabilidad, ahora puesto bajo la óptica de la sostenibilidad, merezca tal revisión. Y que, a partir de ello, la respuesta a la habitabilidad no implique necesariamente un inmueble en propiedad como, por ejemplo, la posesión de un vehículo no necesariamente lo es respecto de la movilidad. Si en el segundo caso la respuesta puede ser un sistema de transporte público multimodal, cuyo impacto ambiental es significativamente menor al transporte privado, en el primero quizás consista en crear un nuevo concepto en edificación.

Aquí es donde cobran importancia los sistemas comerciales alternativos, especialmente aquellos que no ofrecen ya la titularidad de un edificio sino el alquiler del servicio que él presta, que podría sintetizarse en una determinada habitabilidad definida por una superficie, unos espacios flexibles, unas prestaciones de confort, unos valores estéticos, una localización dinámica, etc. Estas nuevas formas de comercialización, como el alquiler de partes o unidades de vivienda desmontable 22 , pueden ser de gran ayuda. Si los recursos se alquilan en lugar de comprarse y están organizados de manera tal que pueden ser recuperados, pueden volver a la fábrica. Y si vuelven a la fábrica, pueden reciclarse.

Uno podría preguntarse si, para intentar cerrar los ciclos materiales en la arquitectura en el sentido recientemente comentado, el camino más adecuado pasa por la creación de un nuevo sistema de producción -a partir de cero- o bien por detectar qué sectores, empresas, técnicas, formas de gestión, sistemas constructivos, etc., presentan las mejores condiciones de partida y, a partir de ellos, intentar una evolución hacia un nuevo modelo. Probablemente ambos caminos son válidos, aunque quizás el segundo sea técnica y económicamente más sencillo de ser asumido por el sector.

En tal sentido, se ha detectado que existen formas alternativas de producción de arquitectura que presentan características de interés para el ciclo cerrado de los materiales, que desde el punto de vista ambiental casi no han sido explotadas aún. Se trata de la construcción modular ligera bajo gestión de alquiler, que permite al término del contrato que todas las unidades regresen al parque industrial, pudiéndose recuperar a partir de ello los recursos invertidos. Es un sistema constructivo que consiste en módulos tridimensionales autoportantes con estructura de acero, madera, hormigón, etc. que admiten cerramientos, revestimientos, pavimentos, cubiertas, carpinterías, etc., de diversos tipos (5). Con los sistemas básicos es posible apilar hasta cuatro niveles de módulos y, para alturas mayores, se recurre a una estructura independiente con la que se pueden alcanzar unas ocho plantas. $Y$ debido al bajo peso del sistema constructivo, que ronda los $150-250 \mathrm{~kg} / \mathrm{m}^{2}$, en la mayoría de los suelos hasta las cimentaciones pueden realizarse de forma tal que una vez que el edificio ha sido desmontado también ellas pueden ser removidas, recuperando el solar en estado natural.

A partir de las reflexiones anteriores pueden proponerse unas primeras claves para el cierre del ciclo de la edificación, cuyo estudio y profundización se abordará más adelante:

- Reducir el número de materiales que conforman el edificio, determinando que sean reciclados, que puedan reciclarse y que supongan un bajo impacto ambiental.

-Disminuir la cantidad de materia por unidad de servicio, incluyendo la consideración de la mochila ecológica.

- Asegurar que el sistema constructivo permita la sustitución de las partes, para hacerlo perfectible, y la desconstrucción total del edificio, para recuperar los materiales básicos empleados (y no una mezcla de ellos).

- Establecer que los materiales nunca saldrán del ciclo técnico industrial, es decir que siempre serán gestionados en reciclaje $y$, a ser posible, empleando en ello energías renovables.

El problema central es crear, más que un sistema constructivo, un modelo de gestión. A partir de esto el interés en la construcción modular no radica tanto en la industrializa- 
CONSTRUCCIÓN CONVENCIONAL

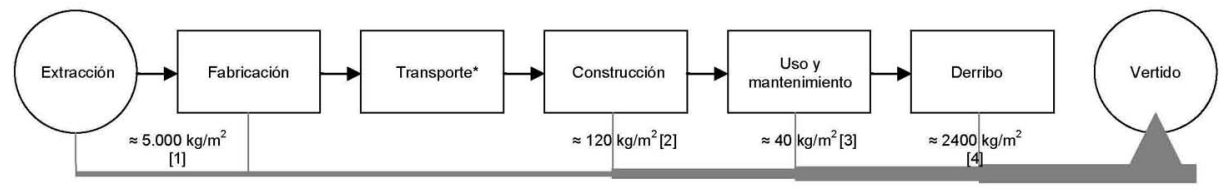

[1] MPS abiótico y biótico menos materiales de construcción

PROPUESTA DE CONSTRUCCIÓN MODULAR EN BASE A EDIFICIOS DESMONTABLES Y DE ALQUILER
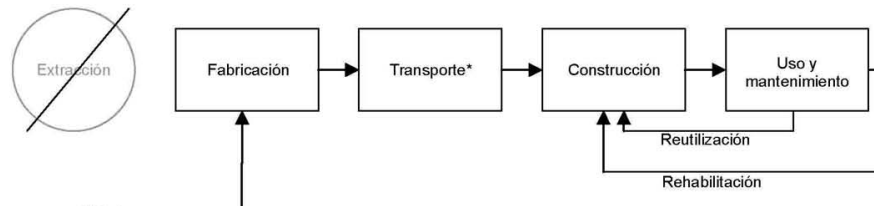

Rehabilitación
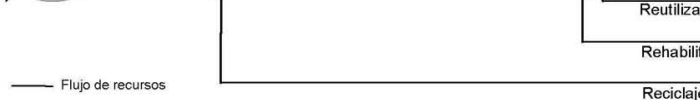

ción en sí misma como en sus condiciones potenciales para cerrar los ciclos materiales (Figura 4).

\section{EVALUACIÓN DE LA SOSTENIBILIDAD DE LOS EDIFICIOS, METODOLOGÍA}

La metodología que permite una valoración exhaustiva del impacto ambiental de los edificios es el análisis de ciclo de vida ACV establecida por las normas ISO 14040/43, puesto que permite cuantificar el impacto medioambiental global realizando una contabilidad completa del consumo de recursos y de la emisión de residuos asociados a las distintas fases del ciclo de vida (6).

No obstante, las metodologías y herramientas relacionadas con el ACV de los edificios no son suficientemente conocidas ni utilizadas entre los agentes del sector de la construcción: promotores, construc- tores, proyectistas, autoridades locales y propietarios de los edificios. La complejidad de su aplicación en una industria de las características de la construcción, el tiempo que requiere su desarrollo respecto de los plazos de realización del proyecto de los edificios y la elevada inversión económica que requeriría su aplicación en ellos con las herramientas y metodologías actualmente disponibles, muchas de las cuales no se encuentran adaptadas a las características específicas del sector en España, hace que su implantación sea muy difícil.

A partir de ello los escasos estudios de ACV sobre edificios que se realizan en España han debido simplificar significativamente la metodología empleada así como realizar diversas adaptaciones y aproximaciones respecto de los datos disponibles en las fuentes de información, que en su mayoría proceden de otros países de Europa o del resto del mundo y tal como se ha dicho no pueden extrapolarse directamente a la situación local. Estos ACV
4. Flujos de materiales en la construcción convencional y en la construcción modular desmontable propuesta.

5. Cuadro síntesis del ACV resumido realizado. 


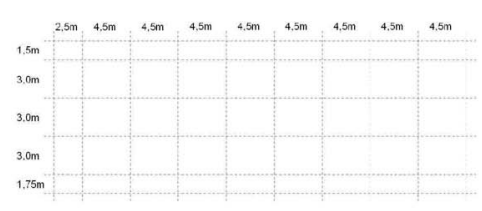

Modulación en planta

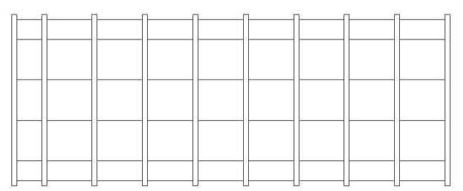

Planta de cimentaciones

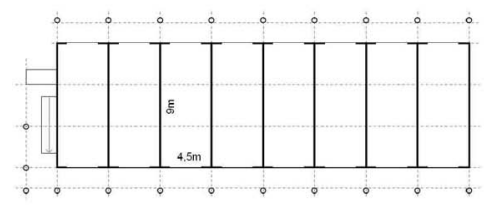

Planta tipo
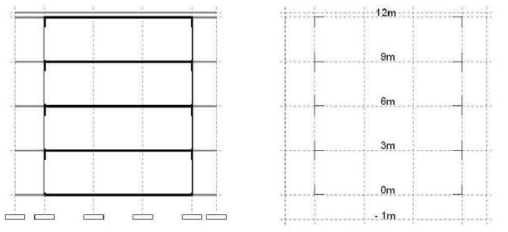

Sección transversal

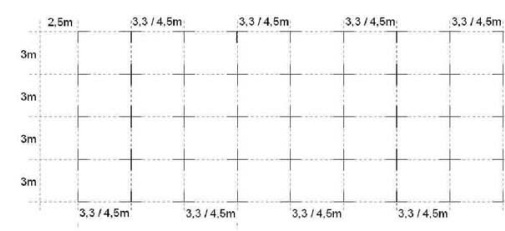

Modulación sección longitudinal

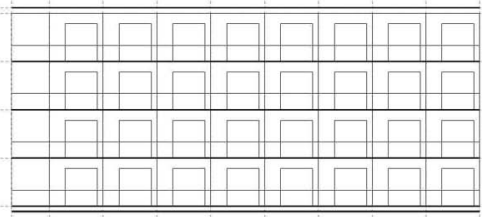

Alzado longitudinal (acceso)

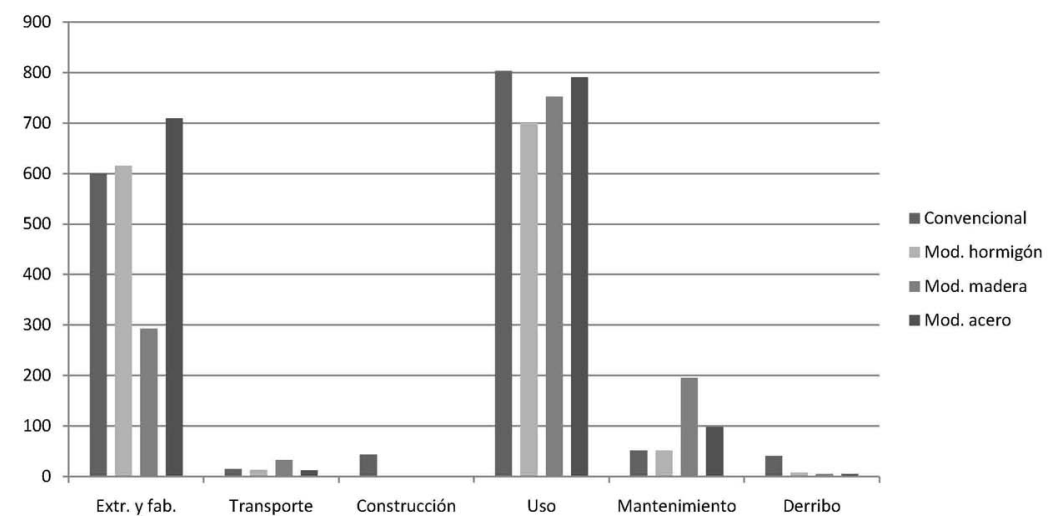

7

6. Esquemas del modelo de edificio utilizado en la evaluación ambiental.

7. Emisiones de $\mathrm{CO}_{2}$ de los cuatro sistemas en el ciclo de vida. habitualmente se realizan en base a pocos indicadores de impacto ambiental y profundizan el estudio en las fases de extracción y fabricación de materiales, por una parte, y de uso y mantenimiento del edificio, por la otra.

En el estudio cuyos resultados se presentarán en los apartados siguientes se ha empleado una metodología de ACV resumido (Figura 5, pág. anterior), ya que resulta de gran utilidad para la evaluación tendencial del impacto ambiental -no así para su determinación con gran exactitud- de la edificación. Entre otras características que facilitan su aplicación en el sector, los ACV resumidos suponen un tiempo de realización de estudios más corto, unas menores cantidades de información necesaria para modelizar el edificio durante las fases del ciclo de vida y sus escenarios y, finalmente, unos menores costes económicos ya que es posible realizar buena parte de ellos con herramientas y fuentes de información de libre disposición, de bajo coste, o de uso público.

En cuanto a las fases del ciclo de vida, se tuvieron en cuenta: 1 . Extracción de materias primas y fabricación de materiales (diversos impactos de los procesos de las industrias extractivas y fabricantes de productos para la construcción). 2. Transporte (impactos de los combustibles empleados en los movimientos que van desde los proveedores de materiales hasta la hipotética localización de la/s obra/s). 3. Construcción o montaje (impactos de la energía empleada por la maquinaria utilizada en obra). 4. Uso (impactos de la energía de calefacción, refrigeración y agua caliente sanitaria, durante 50 años). 5. Mantenimiento y reposición (impactos de los materiales empleados en la conservación y sustitución parcial o total de materiales, durante 50 años). Derribo (impactos de la energía empleada en la demolición y gestión de los residuos generados). Por lo que respecta a los indicadores de impacto ambiental, se tuvieron en cuenta: 1 . Materiales, en $\mathrm{kg} / \mathrm{m}^{2}$ (peso final de la materia de los diferentes elementos que conforman la construcción y el mantenimiento del edificio, de acuerdo con su sistema constructivo). 2. Energía, en $\mathrm{MJ} / \mathrm{m}^{2}$ (consumo energético asociado a todas las fases que tienen lugar durante la vida útil del edificio, como fabricación de materiales, transporte, climatización, etc.). 3. Emisiones de $\mathrm{CO}_{2}$, en $\mathrm{kgCO} / \mathrm{m}^{2}$ (liberación de dióxido de carbono asociada a todas las fases que tienen lugar durante la vida útil del edificio, como fabricación de materiales, transporte, climatización, etc.). 4. Toxicidad ambiental, en $\mathrm{HCA}+\mathrm{HCW} \mathrm{kg} / \mathrm{m}^{2}$ (emisiones o vertidos contaminantes al aire $y$ al agua que tienen lugar durante la vida útil del edificio). 5. Toxicidad humana, en ECAkg/m² (emisiones o vertidos contaminantes al aire y al agua durante la vida útil del edificio). 6. Intensidad material de los materiales, en MIPS t/t (cantidad de materia mineral, vegetal y animal total afectada en los procesos de extracción y fabricación de los materiales). 7. Agua, en $\mathrm{m}^{3} / \mathrm{m}^{2}$ (agua utilizada en los procesos de extracción y fabricación de los materiales y en el uso del edificio). 8. Residuos sólidos en $\mathrm{kg} / \mathrm{m}^{2}$ (residuos de construcción, mantenimiento y derribo o desmontaje). 9. Material reciclado, en \% s/ total (material que efectivamente se ha reciclado respecto del total de materiales, en el inicio de la obra). 10. Material reciclable, en porcentaje sobre el total (material que efectivamente se reciclará respecto del total de materiales, en el final de la obra).

Todo diseño de un ACV resumido tiene un cierto riesgo potencial de incoherencias que 
puede haber entre bases de datos, métodos de evaluación, formas de contar, asunciones, límites del sistema de estudio, etc., que es necesario controlar. En este caso se estableció la exigencia de que, en caso de producirse incoherencias, éstas no supongan un cambio en las tendencias de impacto. Es decir que el margen de incoherencia fue estudiado y limitado mediante la comparación de valores procedentes de distintas fuentes, hasta asegurar que su influencia en los resultados no pueda producir distorsiones que pongan en riesgo la validez de las conclusiones.

\section{ANÁLISIS DE CICLO DE VIDA: SISTEMAS CONSTRUCTIVOS CONVENCIONALES Y MODULARES}

A partir de la metodología de ACV resumido presentada se realizó un estudio comparativo sobre cuatro alternativas constructivas de un mismo edificio tipo, que corresponden a cuatro sistemas constructivos diferentes: convencional o habitual, modular basado en hormigón (Compact Habit), modular basado en madera (Diemodulfabrik KLH) y modular basado en acero (Yorkon). El edificio, de $2000 \mathrm{~m}^{2}$ de superficie, y la célula de vivienda, de $40 \mathrm{~m}^{2}$, que se utilizaron como base para ensayar los cuatro sistemas constructivos, representan una configuración de uso frecuente en vivienda de promoción pública en España ${ }^{23}$ (Figura 6). Sobre cada una de las cuatro variantes del edificio base se desarrolló un análisis ambiental exhaustivo, siguiendo la metodología de ACV resumido descrita en el apartado anterior. Debido a su gran extensión no serán reseñados aquí los resultados obtenidos por cada variante en cada una de sus etapas sino que seguidamente se comentará la síntesis comparativa de todas ellas en base a los indicadores de impacto ambiental más significativos ${ }^{24}$.

Tomando un indicador de indicadores como las emisiones de $\mathrm{CO}_{2}$ para las distintas fases del ciclo de vida (Figura 7), puede comprobarse que aunque existen grandes diferencias en algunas etapas, en el total del ciclo de vida los sistemas tienden a igualarse, debido a su diferente capacidad de respuesta frente a las demandas de cada fase. Materiales como la madera, por ejemplo, obtienen valores muy bajos en extracción y fabricación (7) (8), que no se mantienen cuando se evalúa el transporte (por la localización lejana de su fábrica, en Austria) o el uso (su escasa inercia térmica no le permite retener o ceder calor), aunque aún así es el sistema con mejor desempeño global. En el caso del acero su dependencia de materiales de industrialización intensiva
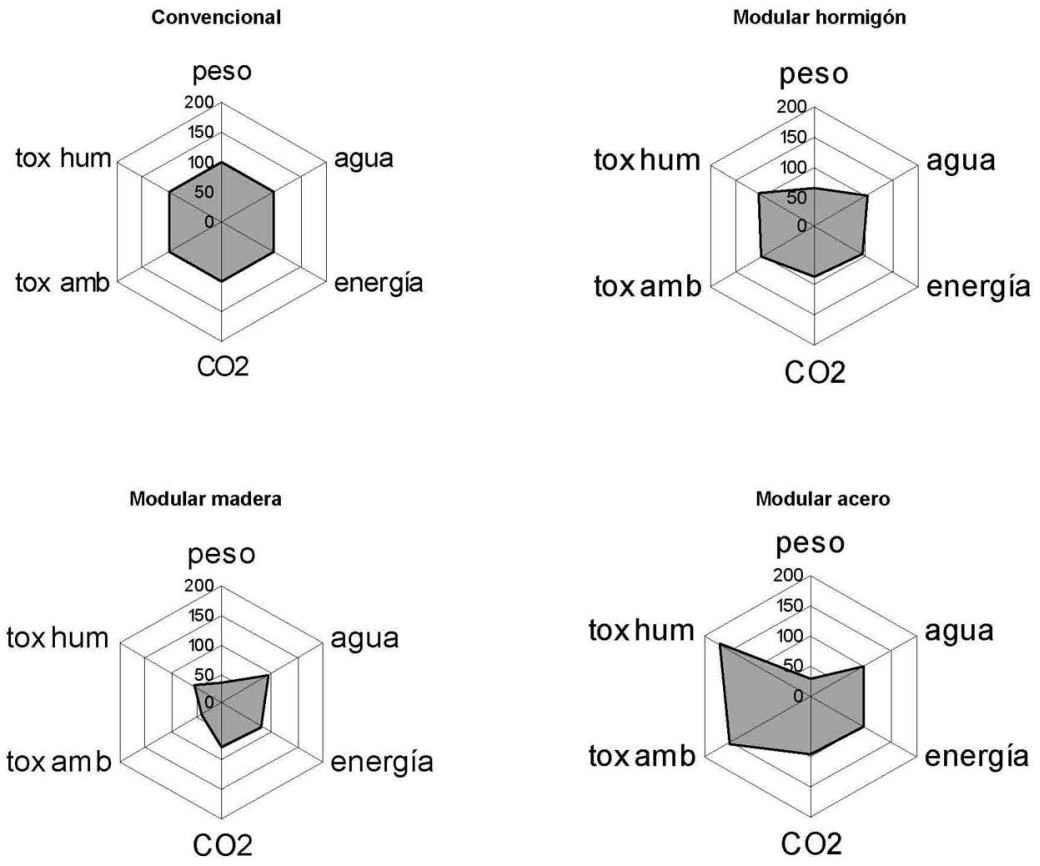

y la baja inercia térmica ya comentada, en el caso de la madera, le impiden obtener buenos resultados. El hormigón compensa un elevado coste en extracción y fabricación con un buen resultado en climatización debido a su capacidad de acumulación térmica. El sistema convencional es la opción de mayor impacto global aunque, comparado con la mejor, representa sólo un $20 \%$ más de emisiones en el ciclo de vida. Se trata de una cifra que confirma que las diferencias en este impacto ambiental y en la dimensión del ciclo de vida no son de gran magnitud y que ligeros cambios en cada uno de estos sistemas podrían alterar las tendencias de esta comparación.

Tomando lectura de diferentes indicadores para el total del ciclo de vida (Figura 8) donde el sistema convencional representa la base de comparación para los otros sistemas, razón por la que presenta un valor de 100\% en los seis indicadores, también es posible establecer una comparación común. La silueta más pequeña y, por tanto, que menores impactos globales representa corresponde a la madera, seguida por el hormigón y por último por el acero, con mayores valores en el área de la toxicidad y menores en cuanto a peso y energía.

Respecto de los indicadores sobre reciclaje, casi todos ellos son bajos a lo largo de las distintas etapas del ciclo de vida. Se registran excepciones en la fase de construcción en los sistemas modulares, que se sitúan entre el 92 y el $97 \%$ de los residuos generados, aunque debe aclararse que casi en su totalidad se
8. Impactos ambientales de los cuatro sistemas en el ciclo de vida.

${ }^{23}$ De acuerdo con las estadísticas del INE, el edificio de viviendas predominante en España es el bloque plurifamiliar de entre 4 y 5 plantas. El proyecto utilizado en este estudio corresponde a un edificio de 32 viviendas que el Intitut Català del Sòl construirá próximamente en Banyoles, provincia de Gerona.

${ }^{24}$ No obstante ello, la información completa puede consultarse en G. Wadel. La sostenibilidad en la arquitectura industrializada. La construcción modular aplicada a la vivienda. (tesis doctoral). 

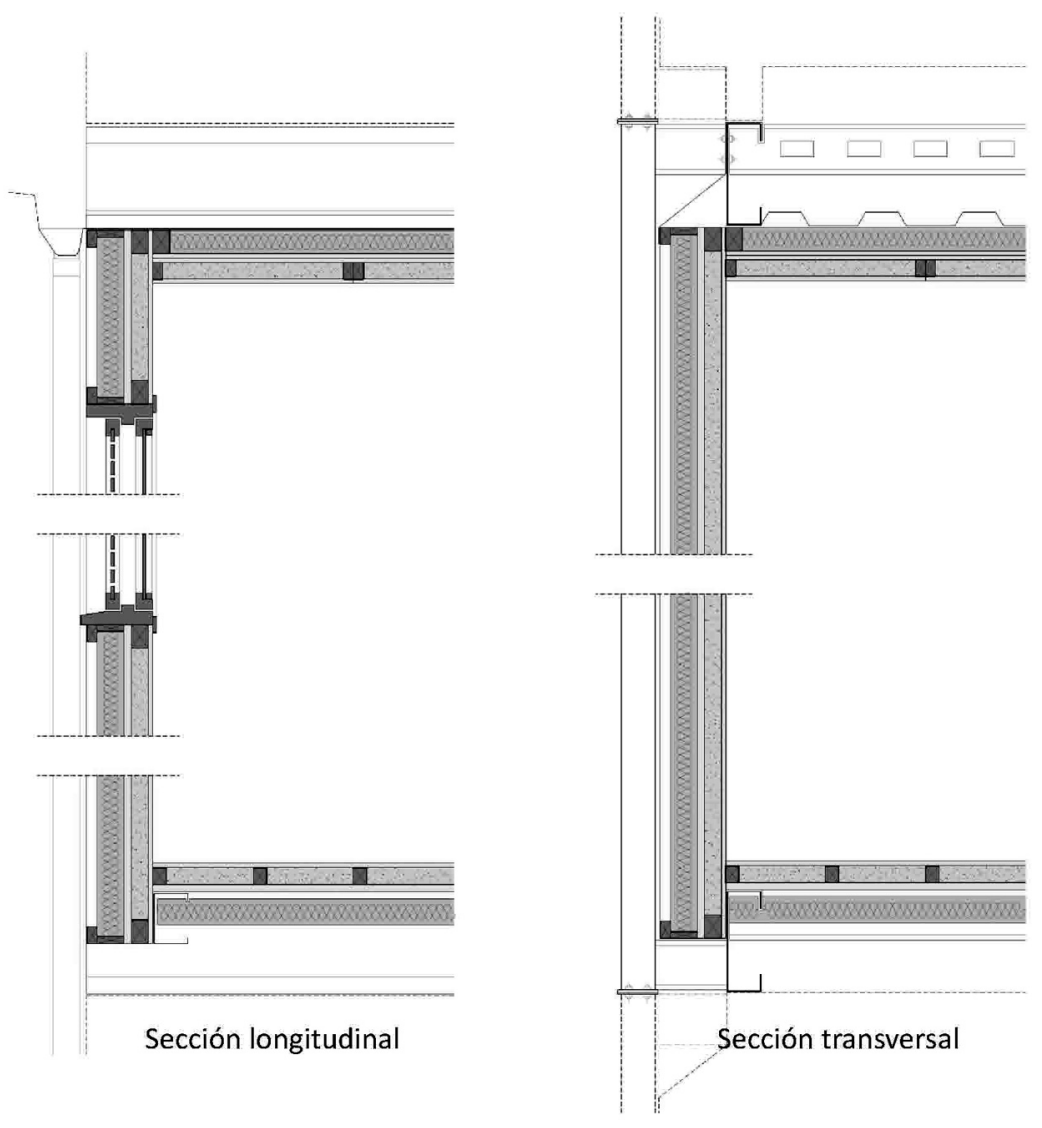

9

9. Secciones constructivas del sistema modular optimizado. La secuencia de capas de materiales, de dentro hacia fuera, es tablero perforado de madera aglomerada (19 mm), grava reciclada $(50 \mathrm{~mm})$, estructura de listones de madera $(50 \mathrm{~mm})$, tablero de madera aglomerada $(22 \mathrm{~mm})$, manto de lana de oveja (40 a $120 \mathrm{~mm}$ según la zona climática), estructura de listones de madera (40-120 mm), membrana transpirable $\left(120 \mathrm{~g} / \mathrm{m}^{2}\right)$, enrastrelado de madera $(25 \mathrm{~mm})$ y chapa de aluminio reciclado $(0,08 \mathrm{~mm})$. trata de pequeñas cantidades de embalajes, acero y madera. En el derribo los sistemas modulares se sitúan entre el $24 \%$ y el $45 \%$, ya que las características del proceso industrial favorecen la recuperación de los materiales. Cuando la mirada se centra en la consideración del cierre del ciclo de los materiales, las diferencias entre el sistema convencional y los modulares se agudizan. Aunque el primero pueda mejorarse y alcanzar valores globales de impacto ambiental más próximos a los sistemas modulares, el consumo de materiales directo (o con la consideración de la mochila ecológica incorporada) los residuos generados a lo largo del ciclo de vida y su escasa reciclabilidad encuentran obstáculos insalvables. Tal como ha sido dicho, los edificios pueden captar más energía renovable que la que gastan y con ello combatir fuertemente el problema de sus emisiones de $\mathrm{CO}_{2}$, pero esta independencia no puede alcanzarse en la dimensión de los materiales. El camino para ello pasa por cerrar los ciclos y en ello, como ha sido explicado antes, el sistema modular de edificios desmontables de alquiler presenta ciertas ventajas comparativas que lo aproximan de forma natural al ciclo cerrado.

Mediante el análisis de la información obtenida es posible establecer ciertas pautas para el próximo paso llevado a cabo en la investigación que se está presentando aquí: el diseño del sistema modular optimizado.

- Extracción y fabricación de materiales: emplear materiales de bajo impacto ambiental, como los naturales renovables y reciclados/ reciclables, y potenciar la reciclabilidad.

-Transporte: emplear los proveedores locales e intentar localizar la fábrica modular cerca de las obras a atender. Racionalizar los movimientos y optimizar cargas.

- Construcción: favorecer al máximo posible la prefabricación del edificio, incluso de las cimentaciones, y la utilización de pocos materiales y juntas reversibles.

- Uso: mejorar el aislamiento térmico y la protección solar, emplear elementos que aporten inercia térmica al sistema. Aumentar la captación de energía renovable.

- Mantenimiento: utilizar materiales durables, de bajo impacto ambiental de fabricación así como de mantenimiento. Y que sean reciclados/reciclables.

-Desconstrucción: utilizar sistemas de junta reversible que potencien la máxima recuperación de los materiales, evitando la generación de residuos.

\section{PROPUESTA DE UN MODELO PARA EL CIERRE DE LOS CICLOS MATERIALES}

Ajustándose al mismo edificio y a la misma metodología, se realizó una quinta evaluación ambiental de ACV resumido, esta vez sobre una propuesta de sistema modular optimizado (Figura 9) formulada a partir de las conclusiones del apartado anterior y en la experiencia del sector de la construcción modular (9).

El sistema modular optimizado tenía como objetivo alcanzar una mejora ambiental en todos los indicadores y aproximarse significativamente al cierre de los ciclos materiales. Para ello se tomaron como base los sistemas modulares analizados anteriormente, especialmente los de madera y acero (por ser ligeros) incorporándoseles en cada fase las siguientes mejoras:

-Extracción y fabricación de materiales: cambio a materiales naturales renovables (por ejemplo, aislamiento térmico de lana de oveja o cerramientos interiores de madera), reciclados y reciclables (por ejemplo, aluminio y acero galvanizado con contenido reciclado en un $90 \%$ o más), baja energía y $\mathrm{CO}_{2}$ incorporados, alta durabilidad y un mantenimiento de baja frecuencia e impacto ambiental. Se intentó combinar equilibradamente distintos criterios: trabajar con el mínimo número de materiales posible, favorecer las opciones de impacto menor y estudiar las posibilidades de gestión 
en ciclo cerrado para diversos materiales. Cabe aclarar que en algún caso los materiales seleccionados no alcanzan a cubrir todas las exigencias normativas, aspecto en el que se tuvo cierta flexibilidad por tratarse de un estudio experimental.

-Transporte: ajuste de las dimensiones del módulo a la norma ISO R-668 que regula las dimensiones de contenedores de transporte multimodal (ancho de 8' o 2,438 m y largos de 40' o 12,192 m, con altura variable). Con ello se evita utilizar equipos especiales y vehículos de acompañamiento, al tiempo que las grúas a emplear son de bajo tonelaje y todos los medios de transporte pueden ser reaprovechados para cualquier otro tipo de cargas de contenedor, una vez que se han descargado los módulos. Cada unidad de vivienda se resuelve empleando el ancho de dos módulos (4,876 m exteriores y aproximadamente 4,476 m interiores), lo que supone la realización de una junta longitudinal en forjados y paredes, así como también que, durante el transporte, una de las caras largas de los módulos debe protegerse con un cerramiento temporal.

-Construcción: el impacto ambiental de la etapa de construcción se concentra en la generación de residuos y otros efectos (energía y emisiones incorporadas, etc.) de la parte de obra que se realiza in situ, básicamente cimentaciones e instalaciones de evacuación. El problema deriva de la utilización de sistemas convencionales de cimentación de hormigón armado, que no permiten recuperar los materiales, así como también de las exigencias normativas de dimensionado (pensadas para edificios de mucho mayor peso), que obligan sobredimensionar y por tanto a utilizar más materiales de los necesarios. Respecto de la primera consideración, se adoptó una solución de cimentación recuperable, consistente en gaviones de piedra y malla de acero galvanizado, ambos reciclados. Respecto de la segunda, el dimensionado de las cimentaciones respondió exclusivamente a las condiciones de carga del edificio (unos $250 \mathrm{~kg} / \mathrm{m}^{2}$ ) y a la hipótesis de carga admisible del suelo (unos $2 \mathrm{~kg} / \mathrm{m}^{2}$ ) y no a los mínimos normativos.

-Uso: la simulación de la demanda energética de climatización, realizada en el capítulo anterior con los programas informáticos LIDER y Ecotect, confirmó que los módulos construidos con sistemas ligeros presentan problemas de acondicionamiento en climas cálidos. A ello responde la incorporación de una cámara de gravas recicladas como primera capa de la envolvente, en el sentido interior-exterior. La cantidad de material empleada, ajustada según su respuesta térmica medida con los programas de simulación, no superó una carga extra superior a los $3.500 \mathrm{~kg} /$ módulo a efectos de hacer posible que los $6.500 \mathrm{~kg} /$ módulo finales puedan ser gestionados con camiones-grúa sin necesidad de recurrir a equipos especiales. El aislamiento térmico (segunda capa) y la protección solar fueron aumentados.

También fueron revisados los tipos de equipos empleados, para mejorar los coeficientes de rendimiento en calefacción, refrigeración y agua caliente sanitaria. Respecto de la calefacción, la hipótesis anterior era un sistema de radiadores alimentados por agua calentada en una caldera individual de condensación a gas con un rendimiento de 0,95. Este equipo, que también se usaba para el agua caliente sanitaria, fue substituido por una bomba de calor reversible central, apoyada con intercambio geotérmico (COP total promedio de 2,6 en calefacción y refrigeración). La contribución solar del agua caliente sanitaria, que era del $60 \%$, fue subida al $70 \%$ teniendo en cuenta que la disposición del edificio permite disponer de suficiente espacio como para alojar los captadores necesarios (unos $80 \mathrm{~m}^{2}$ ) en la cubierta o las barandillas de balcones y accesos. Adicionalmente se incorporó una cantidad equivalente de captadores fotovoltaicos a efectos de reducir el consumo eléctrico no renovable. Naturalmente, los materiales de estas instalaciones se incorporaron al análisis de impacto ambiental.

Finalmente fueron revisadas las pautas de uso consideradas, teniendo en cuenta también en este aspecto un escenario de mayor eficiencia, acorde con el planteamiento general del proyecto de estudio suponiéndose, por ejemplo, un correcto uso de las protecciones solares móviles y de la ventilación natural así como otros mecanismos de ahorro.

-Mantenimiento: bajo los criterios de utilizar materiales de mayor durabilidad, disminuir las cantidades a emplear y escoger las opciones de menor impacto (materiales naturales renovables, materiales industriales comple-
10. Emisiones de $\mathrm{CO}_{2}$ de los cinco sistemas en el ciclo de vida.

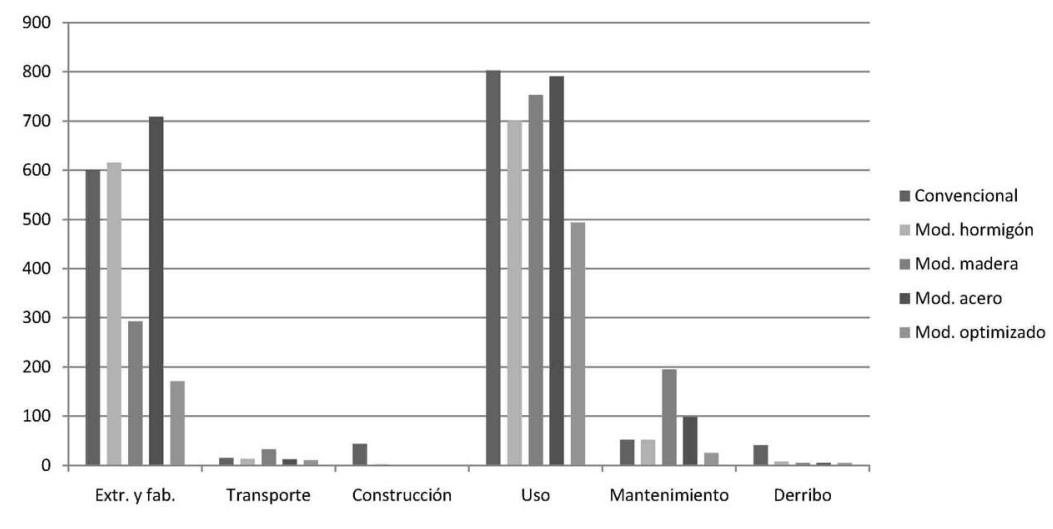



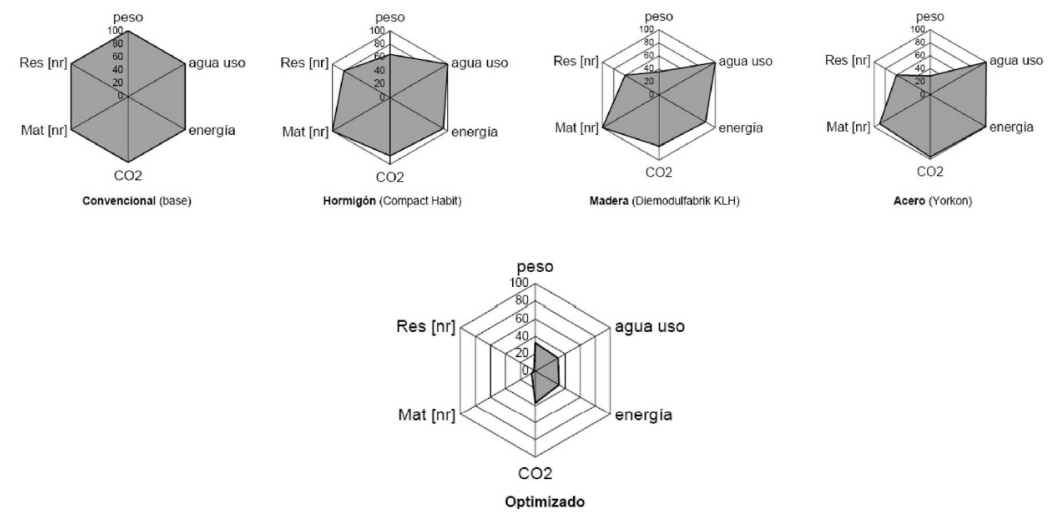

\begin{tabular}{|c|c|c|c|c|c|c|}
\hline \multirow{2}{*}{$\begin{array}{l}\text { Material } \\
\text { Metales }\end{array}$} & \multirow[t]{2}{*}{ Productos predominantes } & \multirow{2}{*}{$\mathrm{Kg} / \mathrm{m}^{2}$} & \multicolumn{2}{|c|}{ Reciclado [1] } & \multicolumn{2}{|c|}{ Reciclable [2] } \\
\hline & & & $\%$ & $\mathrm{~kg} / \mathrm{m}^{2}$ & $\%$ & $\mathrm{~kg} / \mathrm{m}^{2}$ \\
\hline 1 Acero galvanizado & Chapas, perfiles, barras & 45,65 & 96 & 43,82 & 100 & 45,65 \\
\hline 2 Aluminio & Chapas, perfiles y accesorios & 1,15 & 85 & 0,98 & 100 & 1,15 \\
\hline 3 Cobre & Tubos, accesorios y cables & 0,72 & 100 & 0,72 & 90 & 0,65 \\
\hline 4 Bronce & Tubos, accesorios y válvulas & 0,40 & 100 & 0,40 & 90 & 0,36 \\
\hline 5 Latón & Grifería y accesorios & 0,24 & 30 & 0,07 & 90 & 0,21 \\
\hline \multicolumn{7}{|l|}{ Plásticos } \\
\hline 6 Polipropileno [3] & Tubos, accesorios, cables & 1,47 & 85 & 1,25 & 90 & 1,33 \\
\hline 7 Polietileno [4] & Rollos, tubos, depósitos de agua & 1,08 & 100 & 1,08 & 90 & 0,972 \\
\hline 8 Neopreno & Láminas y rollos & 0,42 & 100 & 0,42 & 100 & 0,42 \\
\hline $9 \mathrm{ABS}$ & Cables y accesorios eléctricos & 0,18 & 99 & 0,18 & 80 & 0,14 \\
\hline \multicolumn{7}{|l|}{ Madera y derivados } \\
\hline 10 Tablero aglomerado [5] & Tableros & 91,14 & 100 & 91,14 & 100 & 91,14 \\
\hline 11 Madera & Lamas y listones & 28,50 & 100 & 28,50 & 100 & 28,50 \\
\hline \multicolumn{7}{|l|}{ Otros } \\
\hline 12 Vidrio & Paneles cámara & 6,30 & 30 & 1,89 & 100 & 6,30 \\
\hline 13 Lana de oveja & Rollos y mantos & 2,93 & 100 & 2,93 & 100 & 2,93 \\
\hline 14 Barniz natural & Cajas de botes & 1,52 & 100 & 1,52 & 100 & 1,52 \\
\hline \multirow[t]{2}{*}{15 Árido } & A granel y en losetas & 260,56 & 100 & 260,56 & 100 & 260,56 \\
\hline & & & $95,0 \%$ & 435,5 & $96,4 \%$ & 441,8 \\
\hline Total mats. considerados & 442,26 & $96 \%$ & & & & \\
\hline Total materiales proyecto & 458,31 & $100 \%$ & & & & \\
\hline \multicolumn{7}{|c|}{ [1] Reciclado: material fabricado con residuos de postconsumo o bien con materias primas renovables } \\
\hline \multicolumn{7}{|c|}{ [2] Reciclable: material que efectivamente será reciclado o bien es compostable } \\
\hline \multicolumn{7}{|c|}{ [3] Incluye las tuberías y fundas de cable que originariamente estaban realizados con PVC } \\
\hline \multicolumn{7}{|c|}{$\begin{array}{l}\text { [4] Incluye los depósitos que originariamente estaban realizados con poliéster y fibra de vidrio } \\
\text { [5] Incluye los tableros de particulas de uso interior }\end{array}$} \\
\hline
\end{tabular}

11

11. Impactos ambientales de los cinco sistemas en el ciclo de vida.

12. Materiales que superan el $1 \%$ en peso, energía y emisiones. tamente reciclables, de baja energía incorporada, etc.), se reemplazó la mayoría de los materiales que tenían una vida útil inferior al ciclo de vida del edificio considerado, intentando que alcancen los 50 años (por ejemplo las carpinterías de chapa de acero por madera laminada o los tableros de madera por chapa de aluminio reciclado en fachadas). También se eliminaron los materiales que suponen un consumo frecuente de productos de mantenimiento (por ejemplo el imprimado y pintado periódico por simplemente galvanizado en las estructuras de acero, o los revestimientos exteriores ya citados). Por último, se sustituyeron, especialmente en los casos de corta durabilidad, los materiales de alto impacto ambiental por opciones naturales o completamente reciclables (es el caso de los revestimientos sintéticos adheridos, en las zonas húmedas interiores, por aplacados de piedra natural de reducido espesor fijados mecánicamente, para poder ser separados en la desconstrucción).

-Desconstrucción: además de la disminución del consumo de materiales y la recuperabi- lidad de los mismos, ya comentada en el punto Construcción, otro aspecto importante a destacar es la utilización exclusiva de juntas reversibles, materiales no adheridos (o, en el caso de serlo, de materiales compatibles respecto del reciclado), que favorecen la separación selectiva y por tanto las posibilidades de reutilización directa, rehabilitación o reciclado de materiales.

Recurriendo, al igual que en el apartado anterior, a un indicador de indicadores de impacto ambiental como las emisiones de $\mathrm{CO}_{2}$ (Figura 10, pág. anterior) puede comprobarse que el sistema modular optimizado, comparado con los cuatro sistemas anteriores, disminuye sensiblemente el impacto de las etapas de extracción y fabricación y también de uso. La clave para ello es la sustitución de materiales convencionales por reciclados y naturales, así como la reducción de la demanda de energía, mediante el diseño de la envolvente y el aumento de la eficiencia energética, gracias a la utilización de equipos de mejor rendimiento. Respecto del total acumulado los sistemas convencional y de acero se sitúan en un primer nivel, cercano a los $2.000 \mathrm{~kg} / \mathrm{CO}_{2} / \mathrm{m}^{2}$, ubicándose luego el de hormigón y la madera con algo más de 1.700 y $1.500 \mathrm{~kg} / \mathrm{CO}_{2} / \mathrm{m}^{2}$ respectivamente. El sistema modular optimizado, con un nivel de emisiones sensiblemente menor, se sitúa en los $700 \mathrm{~kg} / \mathrm{CO}_{2} / \mathrm{m}^{2}$ (un $70 \%$ menos que los sistemas convencional y modular de acero y un $50-60 \%$ menos que los sistemas modulares de hormigón y madera).

Respecto de la lectura de diferentes indicadores para el total del ciclo de vida donde el sistema convencional siempre representa la base de comparación, por lo que presenta un valor de $100 \%$ en los seis indicadores (Figura 11), la silueta más pequeña $y$, por tanto, que menores impactos globales representa, corresponde al sistema modular optimizado, seguida por los de madera, hormigón y, por último, acero, con mayores valores en energía y emisiones aunque menores en cuanto a peso, residuos y materiales. Respecto de los indicadores sobre residuos no reciclados (nr) y materiales no reciclados (nr), el sistema modular optimizado obtiene valores muy altos, más del $90 \%$, a diferencia del resto de sistemas en los cuales el mejor de ellos no se supera el $50 \%$.

El estudio ambiental del sistema modular optimizado ha permitido detectar, entre otras cosas ya mencionadas, unos límites y problemas concretos en las mejoras que pueden alcanzarse. En cuanto a los límites, es posible alcanzar una reducción sustantiva en casi todos los indicadores de impacto ambiental-del edificio modular optimizado respecto de las otras opciones estudiadas an- 
tes- mediante los cambios introducidos en cada una de las fases. Esto ha implicado una disminución de un $50 \%$ o más en consumo de materiales, energía, emisiones de $\mathrm{CO}_{2}$, residuos sólidos, etc. En cuanto a la reciclabilidad efectiva de los recursos empleados -la condición de cierre de ciclos materiales que este estudio se propuso llevar al límite máximo posible- las diferencias son aún mayores ya que el sistema optimizado alcanza valores de hasta el 95\% (Figura 12).

No obstante, profundizar aún más en estas mejoras dentro de las restricciones que presentan las técnicas y productos disponibles en el mercado global actualmente -una condición que la investigación se propuso respetar dado que pretende arribar a conclusiones aplicables en la realidad- no resulta sencillo. Han sido alcanzados algunos límites fijados por las técnicas, los productos, o la información existente.

Asimismo, muchas de las mejoras introducidas conllevan efectos negativos. La incorporación de instalaciones de intercambio geotérmico, de recogida de aguas de lluvia, o de captación solar térmica y fotovoltaica, por ejemplo, actúa positivamente en la etapa de uso pero afecta negativamente al consumo de materiales de alto impacto ambiental y sus posibilidades de reciclaje.

Estas consideraciones sobre límites y problemas de las mejoras permiten elaborar algo así como una lista de obstáculos a superar en cada fase:

-Extracción y fabricación de materiales: disponer de materiales con mayor participación de energías renovables, eliminación de procesos tóxicos y reciclaje en sus procesos de fabricación.

-Transporte: aumentar la eficiencia (camiones de menor consumo o combustibles renovables, viajes de regreso a carga completa, etc.) y definir los radios de acción en que las fábricas modulares pueden ser eficientes.

-Construcción: desarrollar cimentaciones propias del sistema, adaptables a diferentes capacidades de carga de suelos, que sean recuperables y reciclables, así como utilizar grúas de menor consumo o impulsadas con energías renovables.

- Uso: reducir la demanda, de acuerdo a las condiciones de cada clima, para controlar más estrictamente la infiltración, la ventilación controlada, la ganancia solar selectiva, etc., así como también disponer de equipos e instalaciones de mayor eficiencia y menores impactos específicos como la toxicidad, en el caso de la energía eléctrica.

-Mantenimiento: disponer de tratamientos naturales para los materiales naturales que aumenten su durabilidad y/o disminuyan el impacto ambiental de cada aplicación.

-Desconstrucción: desarrollar productos de instalaciones que puedan ser descompuestos en materiales simples y reciclables.

\section{SISTEMA INDUSTRIAL Y SISTEMA COMERCIAL}

El estudio de diferentes alternativas constructivas y, posteriormente, la definición y el análisis de un sistema optimizado modular han permitido establecer las características de un sistema constructivo que reduce significativamente el impacto ambiental en el ciclo de vida del edificio escogido como ejemplo. No obstante, para cerrar los ciclos materiales en la edificación no es suficiente con ello, ya que sin contar con un sistema industrial y un sistema comercial (10) acordes no sería posible gestionar sus recursos más allá de la vida útil del propio edificio.

En consecuencia, la gestión para el cierre de los ciclos materiales debe incluir: a) un sistema constructivo modular realizado con materiales reciclados y reciclables, b) un sistema industrial que permita tanto la fabricación como el desmontaje completos para el reciclaje y c) un sistema comercial que garantice el retorno de las unidades a fábrica, que en este trabajo se propone basado el alquiler en lugar de la venta.

Sobre esta hipótesis se ha trabajado bajo el supuesto de que cada material que Ilega a fábrica es de origen reciclado o renovable y que, a la finalización de la vida útil, los módulos regresan a ella para ser desmontados y separados sus materiales. Cuando ya no es posible su reutilización o rehabilitación, ni total ni parcial, el máximo posible de recursos, un $95 \%$ respecto del peso de los materiales empleados según se ha estimado, se reutilizan, rehabilitan o son entregados a recicladores para asegurar que continuarán dentro del sistema técnico industrial reconvirtiéndose en materias primas.

Este flujo de ingresos y egresos de recursos de la fábrica es el que asegura que el sistema pueda cerrar sus ciclos. Para su verificación se partió del supuesto de que las diferentes técnicas, materiales, productos, etc., seleccionados podrían estar presentes algún día en casi cualquier sitio, trabajando como si se dispusiera de la mejor tecnología existente en el mercado local.

Tomando como base al conjunto de materiales de mayor repercusión ambiental (los 15 materiales que superan el $1 \%$ del total en peso, energía o emisiones de efecto invernadero, que en conjunto suponen el $96 \%$ 
del peso total del edificio), se establecieron para cada uno de ellos las condiciones de provisión, montaje, desmontaje y tratamiento final asegurando de esta manera su origen reciclado, su gestión para el reciclaje y su reciclado efectivo. Pudo comprobarse que el reciclaje o la renovación de los materiales puede alcanzar hasta un 95\%.

No obstante se debe tener en cuenta que en el contexto local posiblemente no se pueda hablar de la existencia de demanda y oferta de este tipo de edificios, más que en unos pocos casos. En España el sector de la construcción modular se encuentra casi enteramente dedicado a la comercializan módulos ligeros destinados a edificación temporal, excepto en algunos casos como las empresas Compact Habit, Modultec, Drace, Algeco y otras que realizan edificios que podrían llegar a desmontarse y regresar a fábrica para ser rehabilitados, reutilizados o recuperados sus materiales.

La situación en otros países europeos es diferente: Reino Unido, Alemania, Holanda, Suiza y Austria entre otros, tienen una mayor tradición en la utilización de sistemas constructivos prefabricados y, entre ellos, específicamente en los ligeros y modulares. Bauart Architekten con su sistema Zuri-Modular y ERNE con su sistema Modultech (ambas de Suiza), Spacebox (Holanda), Yorkon (en Reino Unido), die.Modulfabrik (en Austria) y otras empresas fabrican edificios modulares desmontables de alta calidad que, además, presentan condiciones de comercialización muy próximas a los supuestos de este trabajo.

Para que sea posible un sistema industrial que permita montar y desmontar viviendas y un sistema comercial que garantice el retorno de las unidades a fábrica, para cerrar ciclos materiales, podrían tenerse en cuenta las siguientes pautas.

En el rediseño de la industria:

-Cero residuos: utilización de productos fabricados, usados y reintroducidos en el ciclo productivo sin que se produzcan residuos sólidos no aprovechables, ni tampoco emisiones que no puedan ser absorbidas por el medio.

- Reciclado/reciclable: aseguramiento de ambas condiciones a través del sistema técnico (materiales reciclables), del sistema biosférico (materiales renovables), o combinando ambos mediante el reciclado de los materiales renovables.

- Energía renovable: otro salto cualitativo a dar es el cambio de energías no renovables a renovables, ya que las fósiles no cierran sus ciclos materiales. Esta es la clave para reducir, por ejemplo, las emisiones de $\mathrm{CO}_{2}$ incorporadas en los materiales.
-Transporte eficiente: reducción del flujo de cargas, trabajando con materias primas y fábricas locales. Racionalización del flujo de cargas, para que el aprovechamiento de los medios de transporte sea máximo. Utilización de medios más eficientes (menos energía y emisiones por $\mathrm{tm} / \mathrm{km}$ ) como el ferrocarril. $Y$ cambio de energía fósil a renovable.

En el rediseño del comercio:

- Demanda de calidad ambiental: la demanda de calidad ambiental puede crearse, y no sólo esperar a que se produzca. Ejemplos de servicios de movilidad alternativa como Carsharing o Bicing ${ }^{25}$, cuya modalidad comercial es similar a la que aquí se propone para la vivienda, son muy ilustrativos en este sentido.

- Servicios más que productos: el alquiler de habitabilidad mantiene vinculados los recursos con la industria y el comercio a lo largo del ciclo de vida. Los costes están presentes en forma constante, haciendo que aumente la eficiencia en el uso de los recursos y que éstos se mantengan dentro del sistema técnico industrial.

- Inclusión del coste de reposición del capital natural: reflejar los costes ambientales ocultos (como los impactos de los materiales) abriría mercado para las alternativas ecológicamente eficientes. La valoración económica de los derechos de emisiones de gases de efecto invernadero (GEI) es un ejemplo sobre cómo hacerlo.

- La penalización de la ineficiencia: alternativamente, si los precios no reflejan los costes de reposición de capital natural, entonces pueden hacerlo ciertas tasas e impuestos que graven la ineficiencia en la gestión de los recursos.

\section{CONCLUSIONES DEL TRABAJO}

-El planteamiento del estudio respecto de la problemática detectada.

El impacto ambiental de la edificación es consecuencia del modelo de producción lineal extractor de recursos y generador de residuos, que debe cambiarse en el sentido del cierre de los ciclos materiales.

Partiendo de un modelo de edificación con ventajas potenciales, analizado a través de un ACV resumido y de un estudio de cierre de ciclos, la investigación pudo situarse más en las estrategias definitivas que en las paliativas.

-El desarrollo y la verificación de la hipótesis planteada.

Ha podido comprobarse que era posible definir las características principales del 
sistema constructivo, industrial y comercial que hicieran posible la gestión de un modelo de edificación de vivienda plurifamiliar de hasta un $95 \%$ de ciclos cerrados, manteniéndose dentro de las limitaciones que el mercado global presenta.

- La determinación de la metodología de análisis, propuesta y verificación.

Los sistemas usuales de evaluación ambiental no son adecuados para estudiar la edificación bajo la exigencia del cierre de los ciclos materiales. Frente ello se ideó un sistema mixto, el análisis de ciclo de vida resumido vinculado a la evaluación de cierre de ciclos, que permitió construir un modelo de estudio de flujos de recursos materiales.

- Los resultados obtenidos en esta investigación.

Restringiéndose a unas ciertas condiciones constructivas, industriales y comerciales es posible plantear un tipo de edificación que cierre significativamente sus ciclos materiales. La clave no reside ni en un tipo de edificio, ni en un sistema constructivo, ni en unos materiales, sino en el control y la gestión continua de los recursos a lo largo del ciclo de vida, abriéndose muchas posibles aplicaciones en el sector de la edificación.

- Las posibilidades de aplicación de los resultados alcanzados en la industrialización.

Aunque el trabajo se ha centrado en el ámbito de los sistemas prefabricados, modulares y de uso temporal, no se propone que toda edificación se realice con estas técnicas.

De tal forma, otros sistemas industrializados (pesados, mixtos, bidimensionales, de venta, etc.) también pueden cerrar ciclos materiales ya que como se ha dicho, la clave radica más en la gestión continuada de los recursos que en un sistema en particular.
- Los límites que la investigación ha ido encontrando en su desarrollo.

El cierre de los ciclos materiales alcanzado no ha llegado al $100 \%$, pues hay materiales que tienen dificultades técnicas para reciclarse completamente. Tampoco se ha podido extender esta consideración a la energía de extracción, fabricación y transporte de materiales, uso del edificio, derribo, etc., debido a su complejidad. Asimismo, existen límites termodinámicos que impiden llegar a un $100 \%$, ya que todo reciclaje tiene mermas y necesita de un nuevo soporte energético y material para llevarse a cabo.

-Algunas nuevas vías de investigación que pueden abrirse a partir de esta tesis.

Podría plantearse el interrogante de cuántos y qué materiales y sistemas constructivos admiten ser gestionados en ciclos cerrados. También cuántas y qué tipologías y usos de edificios podrían gestionarse manteniendo sus recursos dentro del sistema técnico industrial. Otros sistemas técnicos, desde muy industrializados hasta muy tradicionales también pueden renovar sus recursos en el sistema industrial o en el sistema biosférico.

- La continuidad de la investigación desarrollada.

El trabajo desarrollado continúa actualmente en varias actuaciones: asesoramiento técnico sobre edificios de vivienda promovidos por el Institut Català del Sòl (construcción modular), la redacción de proyecto y posterior construcción de una residencia de estudiantes en la ETSA del Vallès (construcción modular recuperable) y un proyecto de investigación y desarrollo (muro cortina para clima mediterráneo), proyectos todos gestionados en el ámbito de la Universidad Politécnica de Cataluña.

\section{BIBLIOGRAFÍA}

(1) Cuchí, A.: Arquitectura y Sostenibilidad, Universidad Politécnica de Cataluña. Barcelona, 2005.

(2) Anderson, R.: Mid-Course Correction. Toward a Sustainable Enterprise, The Peregrinzilla Press, Atlanta, 1998.

(3) Naredo, J.M. y A. Valero, A. (eds.): Desarrollo económico y deterioro ecológico, Fundación Argentaria/Visor, Madrid, 1999.

(4) W. McDonough, W., Branguart, M.: Cradle to cradle, Mcgraw-Hill Interamericana de España, Madrid, 2005

(5) Davies, C.: The Prefabricated Home, Reaktion books, Trowbridge, 2005.

(6) Aranda, A. et al.: El análisis del ciclo de vida como herramienta de gestión empresarial, Fundación CONFEMETAL, Madrid, 2006.

(7) Hegger, M., Auch-Schwelk, V., Fuchs, M., Rosenkranz, T.: Construction materials manual, Birkhäuser edition Detail, Munich, Alemania, 2006.

(8) Wooley, T., Kimmins, S.: Green Building Handbook: A companion guide to building products and their impact on the environment, Spoon press, Londres, 2000.

(9) Staib, G., Dörrhöfer, A., Rosenthal, M.: Components and systems. Modular building: design, construction, new technologies. Birkhäuser-Detail, Berlin, 2008

(10) Kieran, S. y Timberlake, J.: Refabricating architecture: How manufacturing methodologies are poised to transform building construction, McGraw-Hill, 2003. 


\section{Publicaciones del Instituto Eduardo Torroja-CSIC Números monográficos de Industrialización de Viviendas de Informes de la Construcción}
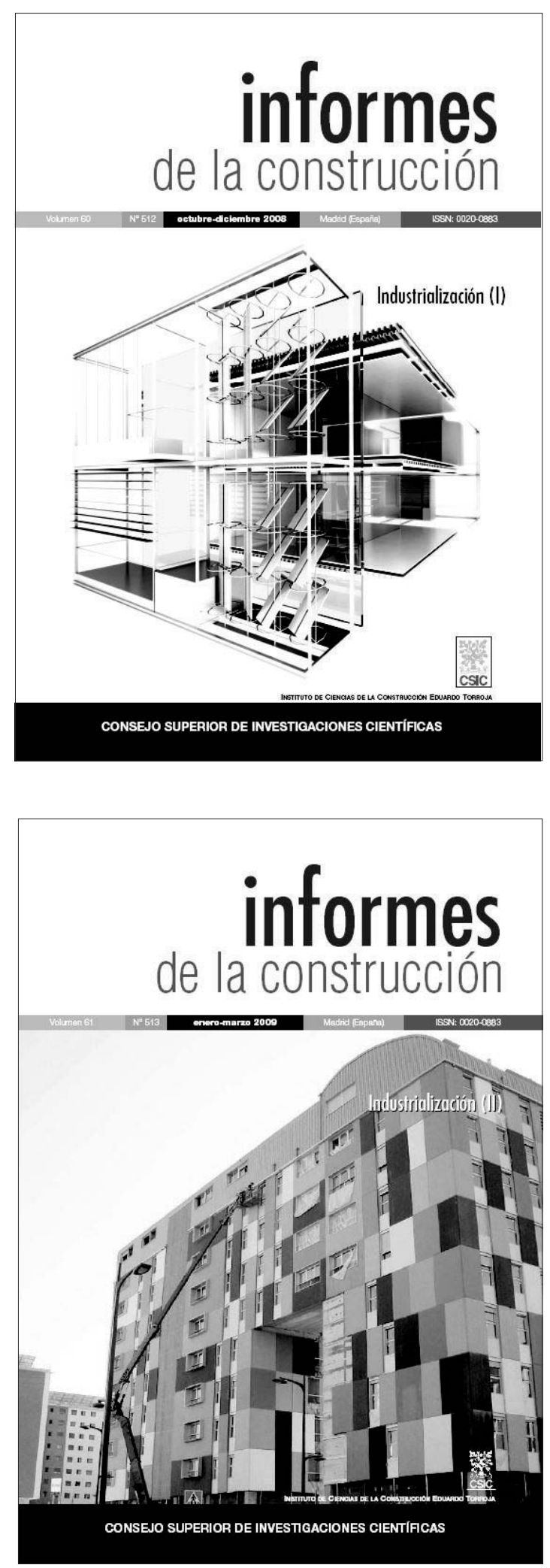

\section{2}

Eduardo Torroja y la industrialización de la "machine à habiter" 1949-1961

Eduardo Torroja and industrialization of the machine à habiter, 19491961

P. Cassinello

De los sistemas de prefabricación cerrada a la industrialización sutil de la edificación: algunas claves del cambio tecnológico

From closed system precasting to the subtle industrialization of building construction: keys to technological change

J. Salas

Arquitectura, Industria y Sostenibilidad

Architecture, Industry and Sustainability

C. Ruiz-Larrea, E. Prieto, A. Gómez

La arquitectura residencial como una realidad industrial. Tres ejemplos recientes

Housing architecture as an industrial reality. Three recent examples

E. Pich-Aguilera, T. Batlle, P. Casaldàliga

d_21 system: un juego para ser habitado

d_system: an play to lived-in

J. M. Reyes, F. Altozano

\section{NOTA TÉCNICA}

Concurso de Ideas INVISO-2008

Design Ideas-INVISO 2008

I. Oteiza, J. Queipo de Llano, G. Gómez

\section{3}

Industrializar

Do it industrial

S. Pérez-Arroyo

Estrategias divergentes de industrialización abierta para una edificación pretenciosamente sostenible

Divergent open industrialization strategies for pretentiously sustainable building construction

J. Salas, I. Oteiza

Habidite: viviendas modulares industrializadas

Habidite: industrialized modular dwellings

V. Gómez-láuregui

El Proyecto Manubuild: una propuesta de la aplicación de sistemas industrializados a la vivienda colectiva en España

The Manubuild Project: an proposal of the application of industrialized systems in the collective housing in Spain

C. Ruiz-Larrea, E. Prieto, A. Gómez, H. Bugueño

Los edificios de paneles más altos de España

The highest buildings made of precast load panels in Spain

A. del Águila, I. Gómez, M. Borsetti, S. Hernando, C. Fernández

\section{NOTAS TÉCNICAS}

Proyecto de investigación INVISO: industrialización de viviendas sostenibles

INVISO research project: industrialization of sustainable houses

J. Queipo, J. M. Navarro, M. Izquierdo, A. del Águila, D. Guinea, M.

Villamor, S. Vega, J. Neila

La innovación tecnológica desde la promoción de vivienda pública:

el Concurso de Innovación

Técnica INCASOL

Technological innovation in public housing developments: the INCASOL Technological Innovation Competition

J. Avellaneda, J. Ma González, G. Marques, J. Vidal

156 Viviendas Industrializadas en Vitoria-Gasteiz

156 Industrialized houses in Vitoria-Gasteiz

J. J. López del Corral 